\title{
CASE FOR DIAGNOSIS
}

\section{An 11-yr-old male with pneumonia and persistent airway obstruction}

\author{
B. Niggemann*, B. Gerstner*, M. Guschmann", K. Paul*, J. Wit", H. Mau", U. Wahn*
}

\section{Case report}

At the age of 4 yrs the male child suffered from a Wilms-tumour of the right kidney treated by polychemotherapy (SIOP No. 9 for stage 1 using actinomycin and vincristin) and surgical removal. A year later, abdominal pain occurred and a local relapse of the Wilms-tumour was diagnosed. Further diagnostics revealed infiltration into the liver, diaphragm, and the thoracic wall. In addition, three lung metastases were found. The child received polychemotherapy again (according to protocol SIOP 93/01 for stage 4 using adriamycin, etoposide, carboplatin, ifosphamide) and radiotherapy of the lung, abdomen (15 Gray) and of the tumour site (35 Gray). The tumour could be resected. All follow-ups during the next 6 yrs showed remission and the child was healthy.

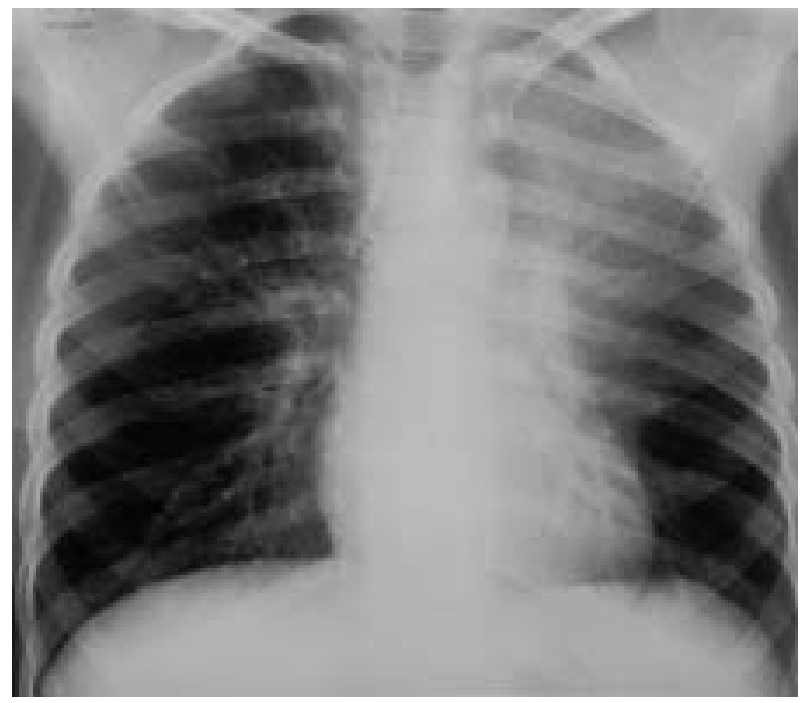

Fig. 1. - Chest radiograph showing an opacity of the left upper field.
At the age of $11 \mathrm{yrs}$, he presented with fever and cough. The chest radiograph showed an opacity of the left upper field (fig. 1). Under the suspicion of pneumonia, antibiotic treatment was started. Due to bronchial obstruction, the child received low-dose inhaled steroids and $\beta$-adrenergic agents. Nonetheless, he still suffered from bronchial obstruction and intermittent fever. Pulmonary function measurement revealed a mixed restrictive and obstructive ventilation disorder (forced vital capacity $52 \%$, forced expiratory volume in one second $49 \%$ and flow at $25 \%$ vital capacity $13 \%$ predicted). Computed tomography (CT) scan of the thorax (including radioopaque material) was performed (fig. 2).

For further diagnosis flexible bronchoscopy was performed, revealing a ball-shaped, soft, solid tumour deriving from the left upper lobe bronchus and bulging into the ostium of the left main bronchus (fig. 3). In order to obtain a thorough diagnosis of the tumour, thoracic surgical intervention was performed. The histology of the tumour revealed typical findings (fig. 4).

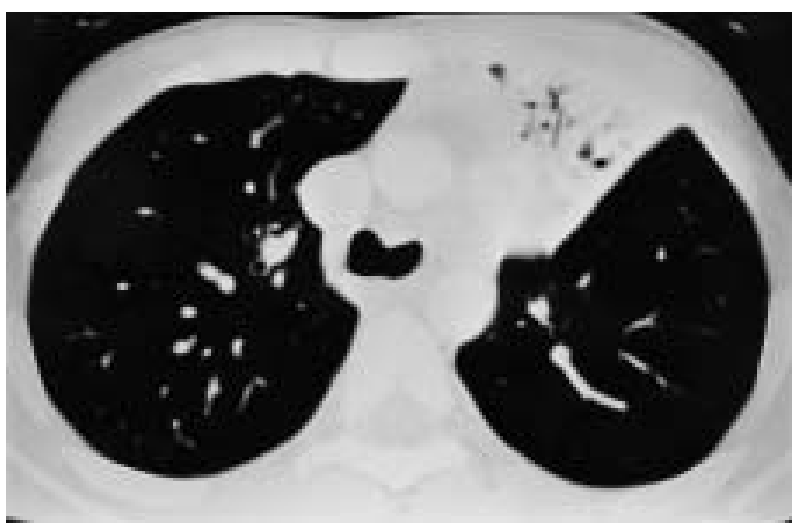

Fig. 2.-Computed tomography scan at tracheal level.

\footnotetext{
*Dept of Paediatric Pneumology and Immunology Dept of Paidopathology and Placentology Dept of Paediatric Surgery, University Hospital Charité, Humboldt University, Berlin, Germany.

Correspondence: B. Niggemann, Dept of Paediatric Pneumology and Immunology, Children's Hospital Charité, Humboldt University, Augustenburger Platz 1, D-13353 Berlin, Germany. Fax: 49 30450566931. E-mail: bodo.niggemann@charite.de
} 

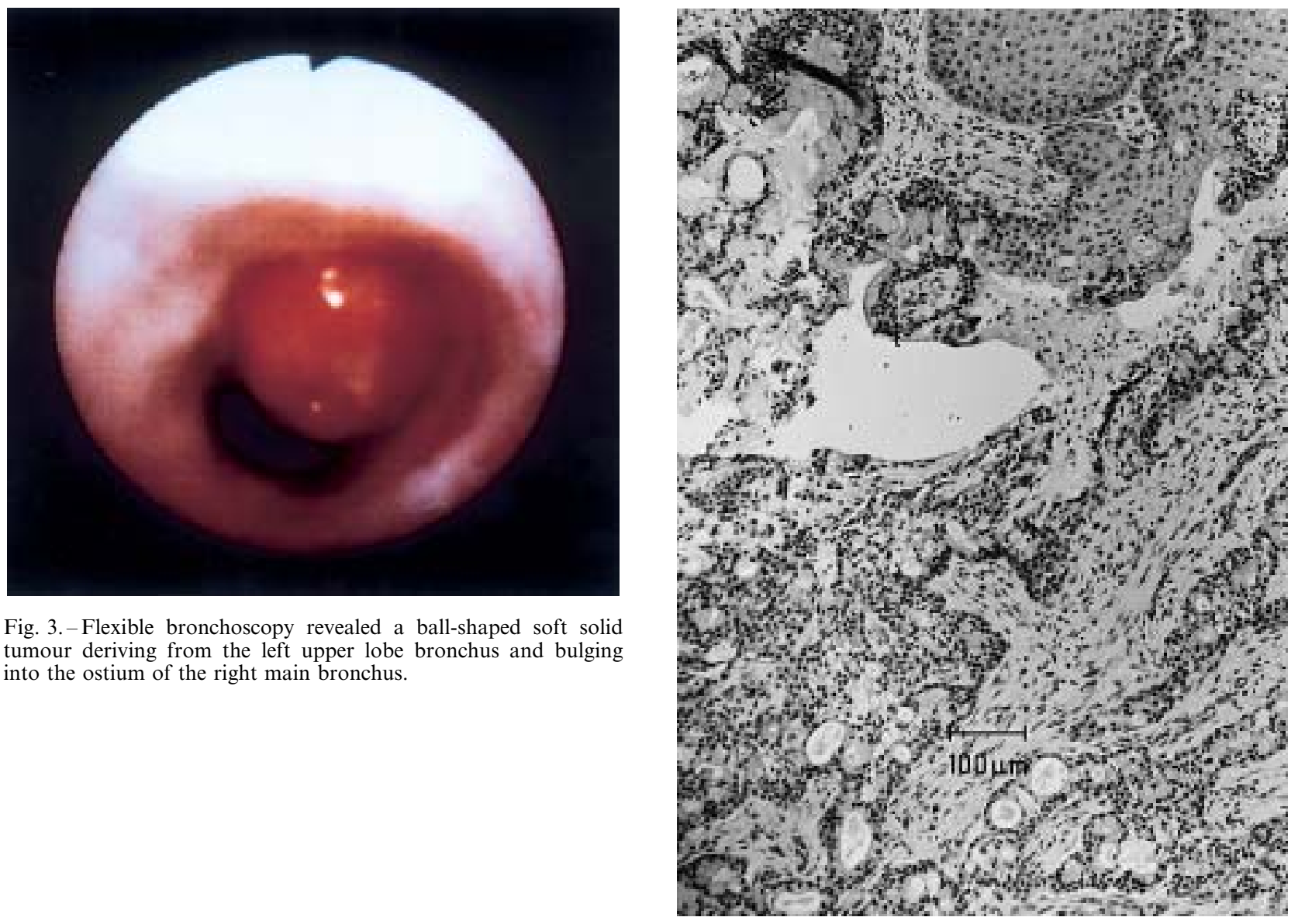

Fig. 4. - Histology of the tumour (haematoxylin and eosin staining).

BEFORE TURNING THE PAGE, INTERPRET THE CT SCAN (FIG. 2) AND THE HISTOLOGY OF THE TUMOUR, AND SUGGEST A DIAGNOSIS. 


\section{Interpretations}

The CT-scan (fig. 2) showed an opaque left anterior upper lobe segment and positive air bronchogram, indicating an atelectasis. The histological work-up (fig. 4) showed a tumour composed of intermediate to high-grade squamous cells forming nests, and mucin-containing glands. There were few mitotic figures and mild nuclear atypia.

\section{Diagnosis: "Mucoepidermoid carcinoma of the left main bronchus, possibly as secondary malignancy in a male child with a history of a Wilms-tumour"}

Successful lobectomy of the left upper lobe and sleeve resection of the upper lobe bronchus led to in toto resection of the tumour. The postoperative course was completely uneventful. The child was in excellent condition and lung function gradually normalized.

\section{Discussion}

Mucoepidermoid carcinoma (MEC) of the lung (formerly called bronchial adenoma) is a rare tumour, especially in children [1-3]. The youngest patients reported were aged 3 [4] and 4 yrs $[5,6]$. The tumour was believed to arise from excretory ducts of submucosal bronchial glands with a common origin of the salivary glands [7]. A recent cytogenetic study indicates that the $t(11 ; 19)$ may be associated with the mucoepidermoid phenotype [8].

Mucoepidermoid tumours of the lung are usually located in the main or segmental bronchi $[2,4,6,8$, 9], with some cases occurring in central airways such as the trachea [7, 10] or carina [1]. Histologically, MEC are classified as low-grade to high-grade carcinomas. Surgical resection is the treatment of choice, using complete excision, lobectomy and/or sleeve resection [11-13].

Children are usually diagnosed following recurrent pneumonias [8, 9, 14-16], persistent cough [1, 9, 11], and/or wheezing (not responding to bronchodilator therapy) $[4,7,8,11,17]$. Some younger children may be misdiagnosed as new-onset asthma [10]. Other children present with atelectasis by complete or partial airway obstruction or with unilateral hyperlucent lungs $[14,17]$. MEC infrequently presents with haemoptysis [16].

In this case, intensive polychemo- and radiotherapy for relapse of the Wilms-tumour may have predisposed for developing secondary malignancy. Usually MECs are regarded as primary pulmonary tumours [18]. The present case may therefore be the first of an MEC presenting as a secondary malignancy in a child.

Fortunately, low-grade malignant tumours are much more common than high-grade ones [19]. Children, especially have an excellent prognosis if low-grade tumours can be resected completely. Therefore, in cases of unclear obstructive symptoms or recurrent pneumonias, a chest radiograph should be used to readily identify suspicious signs followed by further diagnostic steps including bronchoscopy.

\section{References}

1. Kim J, Park CK, Kim K, et al. Surgical resection of mucoepidermoid carcinoma at the carina in a 9-yearold boy. J Pediatr Surg 1998; 33: 1561-1562.

2. Kim TS, Lee KS, Han J, et al. Mucoepidermoid carcinoma of the tracheobronchial tree: Radiographic and CT findings in 12 patients. Radiology 1999; 212: 643-648.

3. Yousem SA, Hochholzer L. Mucoepidermoid tumors of the lung. Cancer 1987; 60: 1346-1352.

4. Anton-Pacheo J, Jimenez MA, Rodriguez-Peralto JL, Cuadros J, Berchi FJ. Bronchial mucoepidermoid tumor in a 3-year-old child. Pediatr Surg Int 1998; 13: 524-525.

5. Seo IS, Warren J, Mirkin LD, Weisman SJ, Grosfeld JL. Mucoepidermoid carcinoma of the bronchus in a 4-year-old child. Cancer 1984; 53: 1600-1604.

6. Noda S, Sundaresan S, Mendeloff EN. Tracheal mucoepidermoid carcinoma in a 7-year-old child. Ann Thorac Surg 1998; 66: 928-929.

7. Stenman G, Petursdottir V, Mellgren G, Mark J. A child with a $\mathrm{t}(11 ; 19)(\mathrm{q} 14-21 ; \mathrm{p} 12)$ in a pulmonary mucoepidermoid carcinoma. Virchows Arch 1998; 433: 579-581.

8. Granata C, Battistini E, Toma P, et al. Mucoepidermoid carcinoma of the bronchus: A case report and review of the literature. Pediatr Pulmonol 1997; 23: 226-232.

9. Torres AM, Ryckman FC. Childhood tracheobronchial mucoepidermoid carcinoma: a case report and review of the literature. J Pediatr Surg 1988; 23: $367-370$

10. Desai DP, Mahoney EM, Miller RP, Holinger LD. Mucoepidermoid carcinoma of the trachea in a child. Int J Pediatr Otolaryngol 1998; 45: 259-263.

11. Bellah RD, Mahboubi S, Berdon WE. Malignant endobronchial lesions in adolescence. Pediatr Radiol 1992; 22: 563-567.

12. Gaissert HA, Mathisen DJ, Grillo HC, Vacanti JP, Wain JC. Tracheobronchial sleeve resection in children and adolescents. J Pediatr Surg 1994; 239: 192 198.

13. Mullins JD, Barnes RP. Childhood bronchial mucoepidermoid tumors. Cancer 1979; 44: 315-322.

14. Allen ED, McCoy KS. Presentation of bronchial mucoepidermoid carcinoma as unilateral hyperlucent lung. Pediatr Pulmonol 1990; 8: 294-297.

15. Archer RL, Grogg SE, Sanders SP. Mucoepidermoid bronchial adenoma in a 6-year-old girl: a case report and review of the literature. $J$ Thorac Cardiovasc Surg 1987; 94: 452-454.

16. Welsh JH, Maxson T, Jaksic T, Shahab I, Hicks J. Tracheobronchial mucoepidermoid carcinoma in childhood and adolescence: case report and review of the literature. Int J Pediatr Otolaryngol 1998; 45: 265273.

17. Patel RG, Norman JR. Unilateral hyperlucency with left lower lobe mass in a patient with bronchial asthma. Chest 1995; 107: 569-570.

18. Cohen MC, Kaschula ROC. Primary pulmonary tumors in childhood: a review of 31 years' experience and the literature. Pediatr Pulmonol 1992; 14: 222-232.

19. Leonardi HK, Jung-Legg Y, Legg MA, Neptune WB. Tracheobronchial mucoepidermoid carcinoma. J Thorac Cardiovasc Surg 1978; 76: 431-438. 